\title{
Predictive Model for Retinopathy of Prematurity in A Tertiary
}

\section{Hospital in Indonesia}

\author{
Aminuddin Harahap ${ }^{\mathrm{a}}$, Martono Tri Utomo ${ }^{\mathrm{a} *}$, Risa Etika ${ }^{\mathrm{a}}$ \\ ${ }^{a}$ Department of Child Health, Faculty of Medicine, Universitas Airlangga/Dr. Soetomo General Academic Hospital, Surabaya, Indonesia \\ Jl. Mayjend Prof. Dr. Moestopo No. 6-8. Surabaya, Jawa Timur, Indonesia 60285 \\ *Corresponding author: Martono Tri Utomo \\ Corresponding e-mail: mrmartono73@gmail.com \\ Corresponding address: Department of Child Health, Faculty of Medicine, Universitas Airlangga/Dr. Soetomo General Academic \\ Hospital, Surabaya, Indonesia. Jl. Mayjend Prof. Dr. Moestopo No. 6-8. Surabaya, Jawa Timur, Indonesia 60285
}

\begin{abstract}
Background: To develop a predictive model for the diagnosis of ROP in Indonesia. In the author's experience, no Indonesian ROP prediction model has been published. Early diagnosis of Retinopathy of Prematurity (ROP) is essential to prevent visual impairment and blindness in the preterm infant. The incidence of ROP reported approximately $65 \%$ of the infant with birth weight $(\mathrm{BW})<1250$ grams and represents a significant clinical problem accounting for up to $40 \%$ of childhood blindness worldwide. Many predictive models had been developed for ROP screening tools in the setting of high-income countries. However, the application somewhat irrelevant to the NICU service condition in the developing countries, including Indonesia. Methods: This retrospective cohort study was performed at Dr. Soetomo General Hospital Surabaya, Indonesia, from May 2009 to April 2011. The ophthalmologist performed binocular indirect ophthalmoscope (BIO) examination to the 248 preterm infants who admitted to the Neonatal Intensive care unit between May 2009 to April 2011. The potential predictors consisted of gestational age (GA), BW, oxygen therapy, sepsis, small for gestational age (SGA), blood transfusion, asphyxia, and respiratory distress syndrome (RDS) were analyzed.

Results: Of the 248 preterm infants, 32(12.9\%) were diagnosed with various stages of ROP. The model had three significant variables: oxygen therapy $(\mathrm{OR}=36.93 ; 95 \% \mathrm{CI}=4.73$ to 288.02$)$, sepsis $(\mathrm{OR}=4.86 ; 95 \% \mathrm{CI}=1.85$ to 12.82$)$, and $\mathrm{SGA}(\mathrm{OR}=$ $3.99,95 \% \mathrm{CI}=1.47$ to 10.82 ). The area below the Receiver Operating Characteristics (ROC) curve was $90.4 \%$. The score had a sensitivity of $89.0 \%$ and a specificity of $78.0 \%$.

Conclusions: This is the first Indonesian predictive model and a scoring system developed for the ROP screening tool of the preterm infant. This simpler tool was expected to reduce the number of ophthalmologic examinations required to detect ROP, especially in resource-limited settings.
\end{abstract}

Keywords: BIO; premature infant; predictive model; ROP; scoring system 


\section{Introduction}

Retinopathy of prematurity (ROP) is the leading cause of preventable childhood blindness around the world. ROP is a multifactorial vasoproliferative retinal disorder in incidence with decreasing gestational age (GA) and is the leading cause of preventable childhood blindness in high- and middle-income countries. $(1,2)$ The suspected ROPs (more often a premature infant) are undergoing the serial eye examination by the ophthalmologist.(3) The number of infants requiring ROP screening is increasing in both high and middleincome countries due to the improved quality of care at the Neonatal Intensive Care Unit (NICU), which increases the survival rate of preterm infants.(4) Current United States (US) screening guidelines recommend at a minimum examining all infants with birth weights (BWs) of 1500 grams or less or estimated GA at the birth of 30 weeks or less. This simple screening model has high sensitivity but low specificity because only about $5 \%$ of infants examined require treatment.(5) However, this US screening method is not suitable in developing countries due to limited facilities, human resources (ophthalmologists), and screening costs. More effective and efficient ROP predictive models are needed following the neonatal service setting in developing countries.

The predictive models quantify the relative importance of individual clinical indicators to evaluate an individual patient's risk of an adverse outcome.(6) These models are an attempt to formally test, simplify, and increase the accuracy of a clinician's diagnostic and prognostic assessment of the ROP. They are most likely to help decide in complex conditions, high stakes medical performance, or lower the hospital cost without bothering the patient's health service.(7) Predictive models are expected to save the clinician's time by screening only infants at the highest risk for ROP requiring treatment and minimalizing the unnecessary examinations performed in low-risk infants.(4) The existing models perform differently depending on the infant population's characteristics and the level of neonatal services provided in their home country. To the best of our knowledge, our institution has no predictive model for ROP screening. It is important for a neonatal tertiary referral center to develop the ROP predictive model for early identification and immediate treatment. This study aimed to develop a predictive model for ROP diagnosis suitable for neonatal service conditions in Indonesia. This study outcome is expected to be widely used to identify the incidence of ROP to reduce childhood blindness.

\section{Subjects and Methods}

This cohort retrospective study was performed at Dr. Soetomo General Hospital Surabaya, Indonesia, from May 2009 to April 2011. The inclusion criteria were all premature newborns with GA $<37$ weeks and BW $<2500$ grams. All the patients who died before a sufficient number of eye examinations or lost to follow up before a sufficient number of eye examinations were excluded in this study. The first eye examination was performed at the four weeks of life. The next screening was conducted at two weeks interval if no signs of ROP were noted in the first examination. Infants with ROP were screened every week or more frequently, depending on the severity. The screening was continued until the retina was fully vascularized, ROP had fully regressed, or ROP had progressed to a stage where treatment was indicated.

The stages of ROP were classified according to the International Classification of Retinopathy. $(8,9)$ If ROP was present in both eyes, the eye with the more advanced disease was used for final staging analysis. All eye examination were carried out by the ophthalmologist who have certification for ROP examination using BIO. 
The ROP predictor parameters in this study were GA, BW, oxygen therapy, sepsis, SGA, blood transfusion, and RDS. The patient's final ROP stage was used to develop the prediction model. The study aimed to create a simple prediction model as ROP pre-screening among preterm babies.

The data analyzed using Statistical Package for Social Science Version 17.0 (SPSS Inc., Chicago, IL, USA). The characteristics of population data are described in the table. Continuous variables with normal distribution were presented as mean (standard deviation [SD]). Independent t-test is used for normally distributed variables, and the Mann-Whitney U test is used for not normally distributed variables. $X 2$ test was used to analyze the categorical variables. The multivariate analysis with multiple logistic regression and calculation of diagnostic test aspects (sensitivity, specificity, and receiver operating characteristics (ROC) Curve) were performed. $P$-VALUES of $<.05$ for univariate analysis and $P$-VALUES $<.1$ for multivariate analysis were considered statistically significant.

A model or formula to predict the probability of a patient experiencing ROP using a formula $y=1 /(1+e-$ $\mathrm{t}) ; \mathrm{y}=$ probability for the occurrence of an event $(\mathrm{ROP}) ; \mathrm{e}=$ natural number $=2.7 ; \mathrm{t}=\mathrm{Constanta}+\mathrm{a} 1 \mathrm{x} 1+\mathrm{a} 2 \mathrm{x} 2$ $+\ldots \ldots . . .+$ aixi (Constanta values and coefficient values for each variable can be seen in column B of the results of the multiple logistic regression analysis); $a=$ the coefficient value of each variable; $x=$ the value of the independent variable. Using these two mathematical equations, we derived the optimal cut-off (probability) that identified infants with and without ROP using a sensitivity and specificity analysis. The optimal cut-offs were derived based on the highest values of sensitivity and specificity, where the sensitivity value must be higher than the specificity value.

\section{Results}

During the two years of the study, a total of 248 premature infants were examined, consist of $52.3 \%$ males and $46.7 \%$ females with a ratio of $1: 1.1$. Thirty-two (12,9\%) of infants were suffered from ROP. The incidence of ROP was more remarkable in females $(62.5 \%)$ than males $(37.5 \%)$, with a ratio of $1: 1.6$. The mean GA of the study population was $32.2 \pm 2.5$ weeks. The mean GA of the infant with ROP was 30.8 (2.9) weeks, while those who did not suffer from ROP were 32.5 (2.3) weeks. The mean BW of preterm infants was 1670.1(344.2) grams, the mean BW of the infant with ROP was 1376.9 (341.6) grams, and the mean BW of the infant without ROP was 1713.6 (323.4) grams. The demographics and clinical characteristics were shown in Table 1. Univariate analysis of all variable are shown in Table 2.

Multiple logistic analysis of GA, BW, oxygen therapy, sepsis, SGA, blood transfusion, and RDS showed three significant parameter of the development of ROP, which oxygen therapy $(P=.001 ; \mathrm{OR}=36.93 ; 95 \%$ $\mathrm{CI}=4.73$ to 288.02$)$, sepsis $(P=.001 ; \mathrm{OR}=4.86,95 \% \mathrm{CI}=1.84$ to 12.82$)$, and $\mathrm{SGA}(P=.007 ; \mathrm{OR}=3.99 ; 95 \%$ $\mathrm{CI}=1.47$ to 10.82$)($ Table 3$)$. 
Table 1. Characteristics of the 248 premature infants included in the study

\begin{tabular}{|c|c|c|c|}
\hline \multirow[t]{2}{*}{ Characteristic } & \multicolumn{2}{|c|}{ ROP } & \multirow[t]{2}{*}{ Total } \\
\hline & $\begin{array}{c}\text { Yes } \\
\text { N(\%) }\end{array}$ & $\begin{array}{c}\text { No } \\
\text { N(\%) }\end{array}$ & \\
\hline \multicolumn{4}{|l|}{ Gender } \\
\hline Male & $12(9.1)$ & $120(90.9)$ & 132 \\
\hline Female & $20(17.2)$ & $96(82.8)$ & 116 \\
\hline \multicolumn{4}{|l|}{ Gestational age (weeks) } \\
\hline$<28$ & $6(28.6)$ & $15(71.4)$ & 21 \\
\hline 29 & $2(20.0)$ & $8(80.0)$ & 10 \\
\hline 30 & $7(30.4)$ & 16(69.6) & 23 \\
\hline 31 & $4(19.0)$ & $17(81.0)$ & 21 \\
\hline 32 & $6(11.5)$ & $46(88.5)$ & 52 \\
\hline 33 & $0(0.0)$ & $28(100.0)$ & 28 \\
\hline 34 & $4(8.7)$ & $42(91.3)$ & 46 \\
\hline 35 & $1(3.7)$ & $26(96.3)$ & 27 \\
\hline 36 & $2(10.0)$ & $18(90.0)$ & 20 \\
\hline Mean GA (SD) [weeks] & $30.8(2.9)$ & $32.2(2.5)$ & \\
\hline \multicolumn{4}{|l|}{ Birth weight (grams) } \\
\hline 750-999 & $4(100.0)$ & $0(0.0)$ & 4 \\
\hline $1000-1249$ & $8(36.4)$ & $14(63.6)$ & 22 \\
\hline $1250-1499$ & $4(8.9)$ & $41(91.1)$ & 45 \\
\hline $1500-1749$ & $12(16.9)$ & $59(83.1)$ & 71 \\
\hline $1750-2000$ & $3(4.5)$ & 63(95.5) & 66 \\
\hline$\geq 2000$ & $1(2.5)$ & 39(97.5) & 40 \\
\hline Mean BW (SD) [grams] & $1376.9(341.6)$ & $1670.1(344.2)$ & \\
\hline
\end{tabular}


Table 2. Univariate analysis of all variables

\begin{tabular}{|c|c|c|c|}
\hline \multirow[t]{3}{*}{ Characteristic } & \multicolumn{2}{|c|}{ ROP } & \multirow[t]{3}{*}{ p-value } \\
\hline & Yes & No & \\
\hline & $\mathrm{N}(\%)$ & $\mathrm{N}(\%)$ & \\
\hline \multicolumn{4}{|l|}{ GA $<32$ weeks } \\
\hline Yes & $19(25.3)$ & $56(74.7)$ & $<0.001$ \\
\hline No & $13(7.5)$ & $160(92.5)$ & \\
\hline \multicolumn{4}{|c|}{$\mathrm{BW}<1501$ grams } \\
\hline Yes & $22(23.4)$ & $72(76.6)$ & $<0.001$ \\
\hline No & $10(6.5)$ & $144(93.5)$ & \\
\hline \multicolumn{4}{|l|}{ Oxygen therapy } \\
\hline Yes & $31(32.0)$ & $66(68.0)$ & $<0.001$ \\
\hline No & $1(0.7)$ & $150(99.3)$ & \\
\hline \multicolumn{4}{|l|}{ Sepsis } \\
\hline Yes & $18(43.9)$ & $23(56.1)$ & $<0.001$ \\
\hline No & $14(6.8)$ & 193(93.2) & \\
\hline \multicolumn{4}{|l|}{ SGA } \\
\hline Yes & $15(25.4)$ & $44(74.6)$ & $<0.001$ \\
\hline No & $17(9.0)$ & 171(90.9) & \\
\hline \multicolumn{4}{|c|}{ Blood transfusion } \\
\hline Yes & $13(40.6)$ & 19(59.4) & $<0.001$ \\
\hline No & $19(8.8)$ & 197(91.2) & \\
\hline \multicolumn{4}{|l|}{ RDS } \\
\hline Yes & 21(30.9) & $47(69.1)$ & $<0.001$ \\
\hline No & $11(6.1)$ & $169(93.9)$ & \\
\hline
\end{tabular}




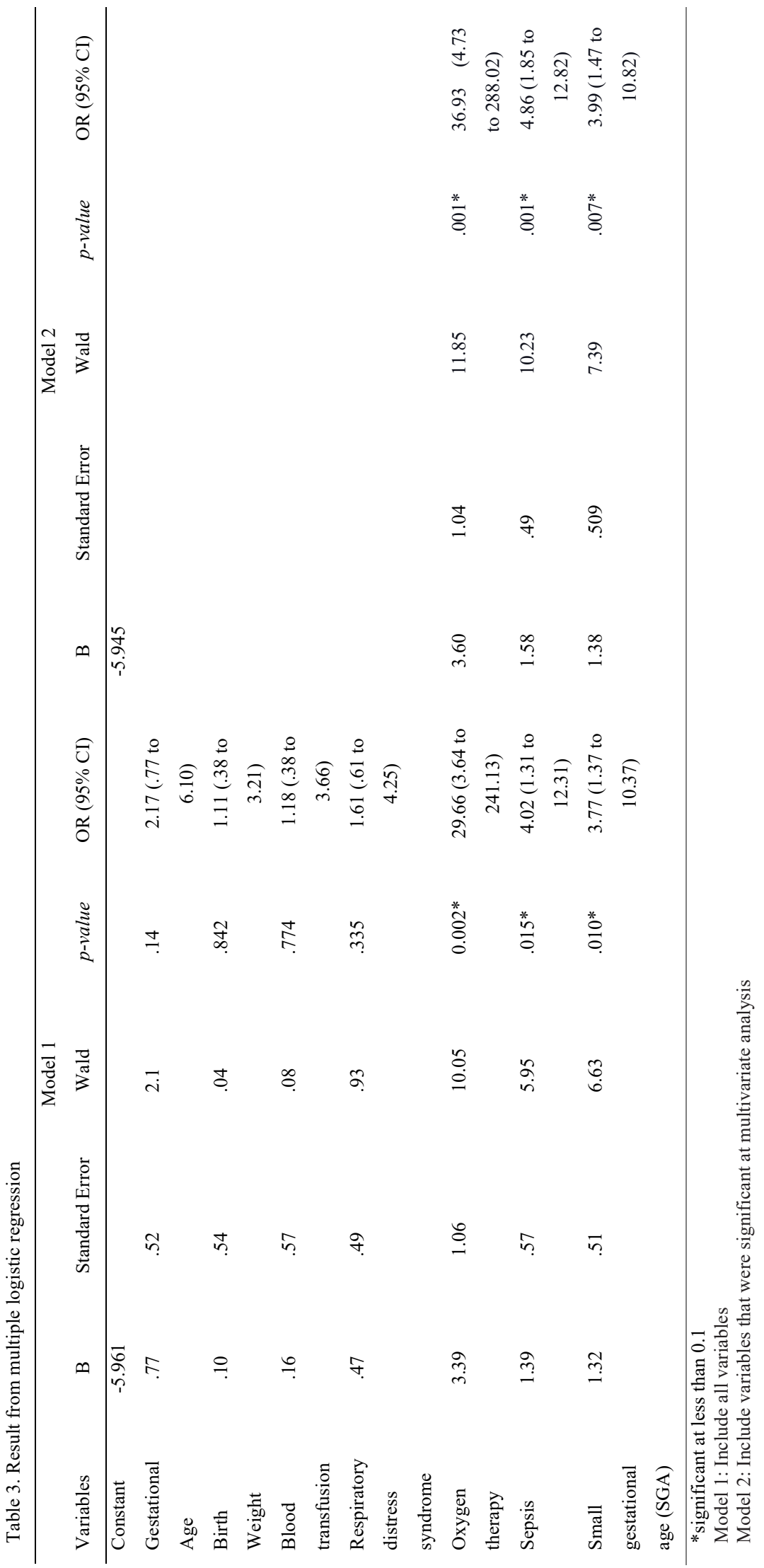


There were three variables in the final regression equation. The result of the regression equation was placed in the exponential equation to calculate the probability. Probability implies the probability to have proven sepsis in this equation and is expressed as a percentage. The coding for this equation are: oxygen therapy $(\mathrm{Yes}=1 ; \mathrm{No}=0)$, sepsis $(\mathrm{Yes}=1 ; \mathrm{No}=0)$, and $\mathrm{SGA}\left(\mathrm{Yes}_{1}=1 ; \mathrm{No}=0\right)$. A model to predict the probability of a patient experiencing ROP using a formula is $\mathrm{p}=1 /\left(1+\mathrm{e}^{-(-5,945+3,609 \text { (oxygen therapy) })+1,582 \text { (sepsis) }+1,384(\mathrm{SGA})}\right)$.

The ROP scoring system was implemented based on the variable coefficients from the final results of the multiple regression analysis. The coefficient value of oxygen therapy is 3.609, rounded to 4 , for sepsis is 1.582 , rounded to 2, and SGA is 1.384 , rounded to 1 . The total ROP score obtained by the sum of the oxygen therapy scores was 4, the sepsis score was 2, and the SGA score was 1 (Table 4).

Table 4. The Indonesian ROP scoring system

\begin{tabular}{ll}
\hline Variables & Score \\
\hline Oxygen therapy & Yes $=4$ \\
Sepsis & No $=0$ \\
& Yes $=2$ \\
Small gestational age (SGA) & No $=0$ \\
& Yes $=1$ \\
& No $=0$ \\
\hline
\end{tabular}

- $\quad$ The maximum score is 7

- The cutoff point of the score is 4

- The patient classified as low risk if the score is less than 4 , and considered high risk if the score is equal or higher than 4

ROC curves determined the accuracy of the ROP Score for predicting the onset of ROP in our population (Figure 1). The AUC value obtained from the ROC curve is $90.4 \%$ (CI 95\% 86.2\%; 94.7\%). The sensitivity and specificity cut-off points were obtained for continuous score values. The best cut-off point established for any stage of ROP was 4 (89,0\% sensitivity and 78,0\% specificity) (Figure 2). Figure 2 illustrates the probability of ROP in preterm infants based on the total ROP score. 


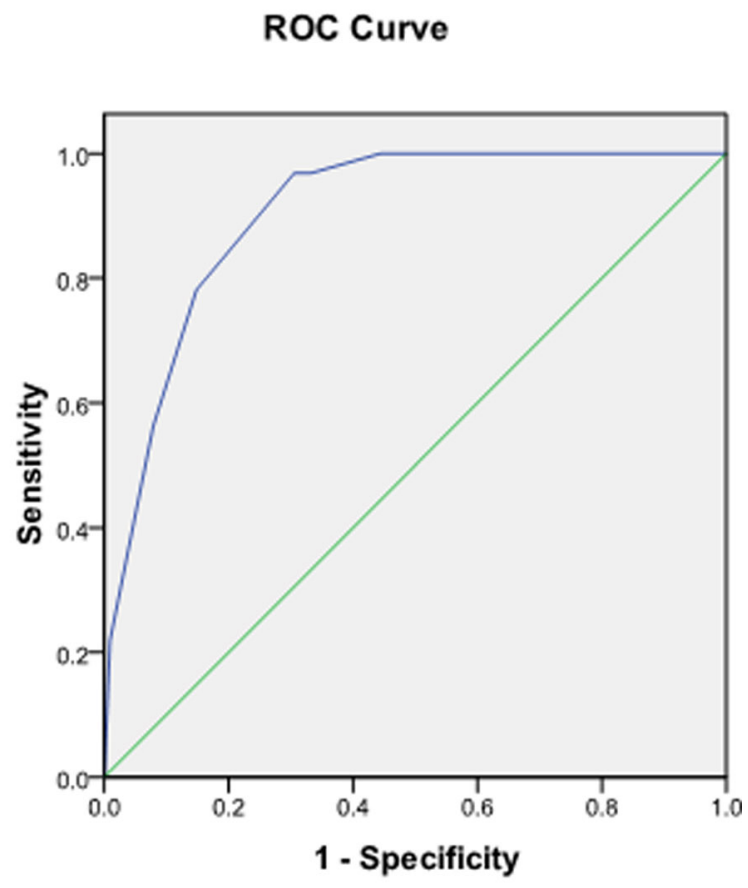

Diagonal segments are produced by ties.

Fig. 1. Receiver operating characteristic (ROC) curves for the detection of any stage of retinopathy of prematurity (ROP)

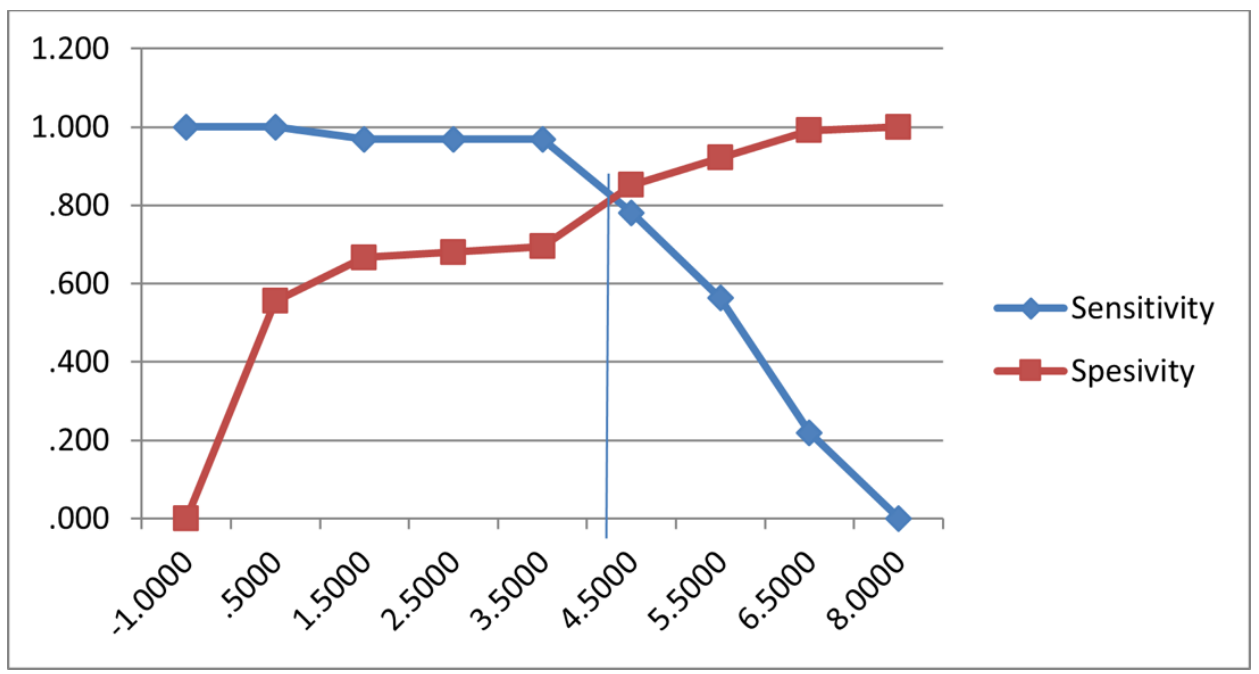

Fig. 2. The cutoff point for the optimum sensitivity and specificity

\section{Discussion}

The predictive models are based on specific parameters to aim for more efficient screening, thereby reducing the number of infants who do not require eye examinations. It also cost-effective and simplify the opthalmologist work.(10) In developing countries such as Indonesia, predictive models are most suitable for limited facilities and limited ophthalmologists.

In the United States, approximately 70,000 preterm infants were screened using their guidelines (BW $<1501$ grams or a GA $\leq 30$ weeks), but only 5\% required treatment.(5) Estimates of preterm births for 184 countries using 2010 data showed that approximately 15 million babies are born preterm annually worldwide. Six countries - India, China, Nigeria, Pakistan, Indonesia, and the United States-account for 50\% $(\sim 7.4$ 
million) of the total preterm birth.(11) In 2010, Indonesia was listed as one of the countries with the most significant preterm births.(12) There were $15.5 \%$ preterm birth of all live births. US guideline is not suitable for Indonesia due to the high number of preterm births in Indonesia will make the screening results less specific and challenging to implement. Other additional parameters are needed so that patients at high risk of ROP and requiring therapy can be appropriately screened. Many screening guidelines based on BW and GA have been published to screening preterm infants who at risk of developing severe ROP. This guide has been adapted to overcome the population characteristics differences in several countries.(13)

The Brazilian guidelines for screening and treating ROP recommend that all preterm infants with GA $\leq 32$ weeks and $\mathrm{BW} \leq 1500$ grams should undergo the fundus examination starting from the fourth to sixth weeks of life until achieving complete retinal vascularization.(14) However, all preterm infants (GA $<37$ weeks and weight $<2500$ grams) were included in the inclusion criteria due to various postnatal risk factors during NICU treatment. Consequently, an excessive number of examinations should be carried out to identify who needs ROP treatment and who doesn't. The examination becomes less effective. The need to optimize the ROP screening for specific patients has led to the development of current predictive models that not only use GA and BW as criteria but also other prominent factors. The comparison between established predictive models are explained in the table below (Table 5).(13,15-22)

Our study identified GA, BW, oxygen therapy, sepsis, SGA, blood transfusion, and RDS as potential risk factor for ROP. However, the final multiple logistic regression analysis showed three independent predictors of ROP development are oxygen therapy, sepsis, and SGA. Based on the results of this study, a predictive model was developed to identify ROP in premature infants. Oxygen-dependent growth factors, such as vascular endothelial growth factor, play a fundamental role in the pathophysiology of ROP.(23) Sepsis induce ROP or increase its severity through several pathogenesis: 1) The pathogen and their endotoxin cause sepsisrelated damage in the vascular endothelial cells by triggers the white blood cells bonding into the blood vessel walls and form microthrombi in the small blood vessels of the retina; these microthrombi results the blood vessel obstruction and increased permeability. Consequently, an area of retinal non-perfusion forms, or the former formed area expands. 2) Sepsis often promotes the body's oxidative stress response, the oxidative stress products promoting vascular endothelial cell proliferation and migration through signalling the vascular endothelial growth factor-2 which leading to retinal cell degeneration and necrosis. 3) ROP is induces and exacerbated by the increasing activity of HIF-1 $\alpha$ due to the effects of inflammatory mediators and growth factors such as interleukin-1 $\beta$. (24-27) Intrauterine fetal growth delay on SGA is associated with a low level of insulin-like growth factor-1 (IGF-1) in utero can inhibit the normal function of vascular endothelial growth factor (VEGF), which interfere with the normal retinal development. $(28,29)$

Hutchinson et al., 2016 conducted a literature review on clinical models and algorithms to predict ROP. He found that various parameters besides GA and BW were weight gain, oxygen therapy, blood transfusion, sepsis, and IGF-1.(4) Binenbaum G, 2016 developed this predictive model by adding postnatal weight gain and has been validated by Vale Lucio KC et al., 2017.(13,15)

Scoring systems have become widely used in neonatology, including neonatal intensive care, to detect comorbidities such as ROP. The ROPScore was developed from predictive models to make it practical and straightforward. Ricard et al., 2017 created a scoring system for ROP screening. The score predicting any ROP was out of 12 points. The score values in each variable are $\mathrm{BW}<750$ grams $=2$ points, $\mathrm{GA}<25$ weeks $=3$ 
points, non-Hispanic mother $=2$ points, respiratory distress syndrome $=3$ points, multiple gestation $=2$ points. A cutoff score of 5 had the best sensitivity (95\%, 95\% CI= 93-97), and AUC was 0.730.(30) Senthil et al., 2015 developed a simple prediction model for the pre-screening of ROP by adding intraventricular hemorrhage (IVH) and respiratory distress syndrome (RDS) beside GA and BW. The sensitivity and specificity for this model was $82 \%$ and $81.7 \%$, respectively.(10)

In our study, the scoring value is derived from the variable coefficient value of the multiple logistic regression test results. The score values are oxygen therapy $=4$, sepsis $=2$, and SGA $=1$, with a total score of 7. The cutoff point for the most optimum sensitivity and specificity was 3.5 ( $96.9 \%$ and $69.4 \%$, respectively). For practical purposes, we set a score limit of 4 . A total score of less than 4 is a low risk of ROP (no need for ROP screening), and a total score of more than or equal to 4 is a high risk of ROP (need for ROP screening) with a sensitivity of $89.0 \%$ and a specificity of $78.0 \%$. Based on the ROC curve analysis results from the ROP score, the AUC value is $90.4 \%$. The AUC value is considered statistically very strong.

There were some limitations in our study. The focus of this study was to establish a prediction model for ROP. Only seven parameters were involved (GA, BW, oxygen therapy, sepsis, SGA, blood transfusion, and RDS) in predicting ROP. These seven variables were well-established as risk factors for ROP in previous studies. Other predictors, such as demographic profile, were not discussed in this study. A significant number of the patient was loss to follow-up to the opthalmologist. This loss to follow-up may occur because of the communication failure between the parents and the clinician.

This study also did not use a new data set. However, our result had been compared to the more recent literature and still appropriate for some settings, especially for developing countries. Our predictive model was based on single center data. External validation is required to improve the accuracy of our predictive model.

\section{Conclusion}

Our predictive models enable effective and efficient ROP screening, especially in the resource-limited setting. This tool is expected to reduce the number of eye examinations required to detect ROP. External validation should be done soon to assess the actual performance in the other institutions.

Competing interest: All authors declare no conflict of interest.

Funding: This research did not receive any specific grant from funding agencies in the public, commercial, or not-for-profit sectors.

Ethical Standard: This study obtained permission from the Institutional Ethical Committee of Dr. Soetomo General Academic Hospital (No. 48/Panke.KKE/III/2011).

\section{References}

1. Leeman K, VanderVeen D. Retinopathy of Prematurity. In: Cloherty and Stark's Manual of Neonatal Care. 8th ed. Philadelphia: Wolters Kluwer Medknow Publications; 2017. p. 986-92.

2. Kong L, Fry M, Al-Samarraie M, Gilbert C, Steinkuller PG. An update on progress and the changing epidemiology of causes of childhood blindness worldwide. Journal of AAPOS. 2012;16(6):501-7.

3. Ying G. A Prediction Model for Retinopathy of Prematurity-Is It Ready for Prime Time? BMC Ophthalmology. 2019; 
4. Hutchinson AK, Melia M, Yang MB, Vanderveen DK, Wilson LB, Lambert SR. Clinical Models and Algorithms for the Prediction of Retinopathy of Prematurity A Report by the American Academy of Ophthalmology. Opthalmology. 2016;123(4):804-16.

5. Lin L, Binenbaum G. Prediction Models for Retinopathy of Prematurity. Advances in Ophthalmology and Optometry. 2018;

6. McGinn TG, Guyatt GH, Wyer PC, Naylor CD, Stiell IG, Richardson WS. Users' guides to the medical literature XXII: How to use articles about clinical decision rules. Journal of the American Medical Association. 2000;284(1):79-84.

7. Sanders S, Doust J, Glasziou P. A systematic review of studies comparing diagnostic clinical prediction rules with clinical judgment. PLoS ONE. 2015;10(6):e0128233.

8. Patz A. An International Classification of Retinopathy of Prematurity: II. the Classification of Retinal Detachment. Archives of Ophthalmology. 1987;105(7):905.

9. Quinn GE. The international classification of retinopathy of prematurity revisited: An international committee for the classification of retinopathy of prematurity. Vol. 123, Archives of Ophthalmology. American Medical Association; 2005. p. 991-9.

10. Senthil MP, Salowi MA, Bujang MA, Kueh A, Siew CM, Sumugam K, et al. Risk factors and prediction models for retinopathy of prematurity. Malaysian Journal of Medical Sciences. 2015;22(5):57-63.

11. Walani SR. Global burden of preterm birth. International Journal of Gynecology and Obstetrics. 2020;150(1):31-3.

12. Sungkar A, Fattah ANA, Surya R, Santoso BI, Zalud I. High preterm birth at cipto mangunkusumo hospital as a national referral hospital in Indonesia. Medical Journal of Indonesia. 2017 Sep 1;26(3):198-203.

13. Do Vale Lucio KC, Bentlin MR, de Lima Augusto AC, Corrente JE, Carregal Toscano TB, El Dib R, et al. The ROPScore as a screening algorithm for predicting retinopathy of prematurity in a Brazilian population. Clinics. 2018;73(9):1-5.

14. Zin A, Florêncio T, Filho JBF, Nakanami CR, Gianini N, Graziano RM, et al. Brazilian guidelines proposal for screening and treatment of retinopathy of prematurity (ROP). Arquivos Brasileiros de Oftalmologia. 2007;70(5):875-83.

15. Binenbaum G. Algorithms for the Prediction of Retinopathy of Prematurity Based on Postnatal Weight Gain. Clinics in Perinatology. 2013;40(2):261-70.

16. Löfqvist C, Hansen-Pupp I, Andersson E, Holm K, Smith LEH, Ley D, et al. Validation of a new retinopathy of prematurity screening method monitoring longitudinal postnatal weight and insulinlike growth factor I. Archives of Ophthalmology. 2009;127(5):622-7.

17. Löfqvist C, Andersson E, Sigurdsson J, Engström E, Hård AL, Niklasson A, et al. Longitudinal postnatal weight and insulin-like growth factor I measurements in the prediction of retinopathy of prematurity. Archives of Ophthalmology. 2006 Dec 1;124(12):1711-8.

18. Desai S, Athikarisamy SE, Lundgren P, Simmer K, Lam GC. Validation of WINROP (online prediction model) to identify severe retinopathy of prematurity (ROP) in an Australian preterm population: a retrospective study. Eye (Basingstoke). 2020;3-8. 
19. Sanghi G, Narang A, Narula S, Dogra MR. WINROP algorithm for prediction of sight threatening retinopathy of prematurity: Initial experience in Indian preterm infants. Indian Journal of Ophthalmology. 2018 Jan 1;66(1):110-3.

20. Binenbaum G, Ying GS, Quinn GE, Dreiseitl S, Karp K, Roberts RS, et al. A clinical prediction model to stratify retinopathy of prematurity risk using postnatal weight gain. Pediatrics. 2011 Mar 1;127(3):e607-14.

21. Binenbaum G, Ying GS, Quinn GE, Huang J, Dreiseitl S, Antigua J, et al. The CHOP postnatal weight gain, birth weight, and gestational age retinopathy of prematurity risk model. Archives of Ophthalmology. 2012 Dec 1;130(12):1560-5.

22. Eckert GU, Fortes Filho JB, Maia M, Procianoy RS. A predictive score for retinopathy of prematurity in very low birth weight preterm infants. Eye. 2012;26(3):400-6.

23. Pierce E, Foley E, Smith L. Regulation of vascular endothelial growth factor by oxygen in a model of retinopathy of prematurity. Arch Opthalmol. 1996;114.

24. Gupta V, Dhaliwal U, Sharma R, Gupta P, Rohatgi J. Retinopathy of prematurity--risk factors. Indian J Pediatr. 2004;71(10):887-92.

25. Wang X, Tang K, Chen L, Cheng S, Xu H. Association between sepsis and retinopathy of prematurity: A systematic review and meta-analysis. Vol. 9, BMJ Open. BMJ Publishing Group; 2019.

26. Lee J, Dammann O. Perinatal infection, inflammation, and retinopathy of prematurity. Vol. 17, Seminars in Fetal and Neonatal Medicine. NIH Public Access; 2012. p. 26-9.

27. Huang J, Tang Y, Zhu T, Li Y, Chun H, Qu Y, et al. Cumulative evidence for association of sepsis and retinopathy of prematurity. Medicine. 2019 Oct 1;98(42):e17512.

28. Fleck BW, McIntosh N. Retinopathy of prematurity: Recent developments. NeoReviews. 2009;10(1).

29. Smith LEH. IGF-1 and retinopathy of prematurity in the preterm infant. Biology of the Neonate. 2005;88(3):237-44.

30. Ricard CA, Dammann CEL, Dammann O. Screening Tool for Early Postnatal Prediction of Retinopathy of Prematurity in Preterm Newborns (STEP-ROP). Neonatology. 2017 Aug 1;112(2):1306. 